\title{
FOOD SECURITY AND LOW-INCOME HOUSEHOLDS IN THE MALAYSIAN EAST COAST ECONOMIC REGION: AN EMPIRICAL ANALYSIS
}

\author{
Md. Mahmudul Alam* \\ School of Economics, Finance \& Banking \\ College of Business, Universiti Utara Malaysia \\ Kedah, Malaysia \\ E-mail: rony000@gmail.com \\ Tel: +601-6279 9091 \\ Chamhuri Siwar \\ Emeritus Professor
Institute for Environment and Development (LESTARI)
National University of Malaysia (UKM)
43600 UKM Bangi, Selangor Darul Ehsan, Malaysia
E-mail: csiwar@ukm.my

\author{
Abu N.M. Wahid \\ Managing Editor, the Journal of Developing Areas \\ Professor, Department of Economics and Finance \\ Tennessee State University \\ Nashville, Tennessee, USA \\ E-mail: awahid@tnstate.edu \\ Tel: +615-963-7149 \\ Basri Abdul Talib \\ Associate Professor \\ Faculty of Economics and Management \\ National University of Malaysia (UKM) \\ 43600 UKM Bangi, Selangor Darul Ehsan, Malaysia \\ E-mail: basri@ukm.my \\ *corresponding author
}

\section{Citation Reference:}

Alam, M.M., Siwar, C., Wahid, A.N.M., and Talib, B. 2016. Food Security and LowIncome Households in the Malaysian East Coast Economic Region: An Empirical Analysis. Review of Urban \& Regional Development Studies, Vol. 28(1), pp. 2-15. [Online Link]

This is a pre-publication copy.

The published article is copyrighted by the publisher of the journal. 


\title{
FOOD SECURITY AND LOW-INCOME HOUSEHOLDS IN THE MALAYSIAN EAST COAST ECONOMIC REGION: AN EMPIRICAL ANALYSIS
}

\begin{abstract}
This research aims at analyzing the level of food security among some selected poor and lowincome households in Malaysia. The study area is located in the East Coast Economic Region of the country. It uses primary data collected during the July-October months of 2012 and 460 sample families were chosen from the E-Kasih poor households database based on cluster random sampling technique. In this sample survey, households' food security has been measured by the USAID-HFIA model. The findings of the study indicate that $52.8 \%$ of the households are food secure, that of $23.3 \%$ are mildly food insecure, $14.3 \%$ are moderately food insecure, and $9.6 \%$ are severely food insecure. The findings on the current situation of household food security among different economic groups is very important for the policy makers to achieve Vision 2020 and the targets of Malaysian National Plans regarding food security, socioeconomic development and poverty alleviation. In order to ensure food security in Malaysia, especial focuses are needed for those who are severely food insecured and those who are food insecured but marginally above the poverty line. Here the involvement of private sector and community based organizations are also important to combat the short run, seasonal, and event related risk of food insecurity as well as for the development of appropriate mitigation and adaptation options to ensure sustainable food security at household level in Malaysia.
\end{abstract}

Keywords: Household Food Security; Household Food Insecurity Access (HFIA); RASCH Model; Monte Carlo Simulation; Malaysia; East Coast Economic Region.

JEL Classifications: I32, Q54, P48

Corresponding Author's Email Address: rony000@gmail.com

\section{Introduction}

It is widely held that the global food crisis of 2008 was not only a problem for that time, but also a sign of a deeper and wider challenge for the world in the subsequent years. According to experts, it is time to make serious preparations to meet this crisis that may revisit the world in the near future. Thus, food security is a burning issue and of great concern for many nations on the face of the earth.

At national level, the adequacy of domestic food production or capability to mobilize food on time from international market may be sufficient. However, it does not automatically guarantee sustained food security at household level. The factors determining food security at household level are more crucial than those at national level. When "food security" is defined as access by all people at all times to the food needed for a healthy life (FAO 2003:28), the focus of "food security" is on households as basic units of society. This assertion is important, as strategies directed toward improving food security for households may be quite different from those aimed at ensuring the same for the country as a whole.

Food security at household level is considered so important now that developed countries are also putting more emphasis on this issue. For example, it was found that $16.9 \%$ of the population in the US was at risk of household food insecurity during the duration of the five year period, and $14.5 \%$ of the households faced food insecurity at some point in 2010 
(Parke et al. 2010). If it was the scenario of a developed nation, it was also very important to find out the scenario for the developing world. As a case study, therefore, this study looks at the status of Malaysia. The focus on Malaysia is justified for several reasons. Among the developing nation, Malaysia is one of the emerging economies which has successfully developed a policy of enviable economic growth and also planned to become a fully developed nation by the year of 2020, which is known as the Vision 2020 of Malaysia.

Malaysia joined 185 other nations in signing the Declaration of Rome at the 1996 International Food Summit, pledging to reduce the prevalence of hunger by at least $50 \%$, within its own jurisdiction, by a target date some time in the early $21^{\text {st }}$ century. However, in Malaysia, the food security has been embedded into the theme of self-sufficiency level that referred to paddy or rice sector only (Alam et al. 2011;2012a), instead of having a specific or special policy on overall food security. To ensure food security in Malaysia, the government adopts two strategies, such as establishing self-sufficiency level and building rice stocks both domestically and internationally. However, Malaysia has had never met the food selfsufficiency level. About $10 \%$ to $35 \%$ of total required rice is imported from neighboring countries, such as Thailand, Vietnam, Myanmar, India, and Pakistan. The highest food selfsufficiency level for the country was $95 \%$ and the lowest was $65 \%$, which were recorded in 1975 and 1990 respectively.

Regarding the status of food security in in Malaysia, studies have shown that among low-income rural communities, $50 \%$ or more of the households face some level of food insecurity with $34.5 \%$ child hunger (Shariff and Khor 2008). They also show that households with food insecurity have been characterized by more children, larger size families, more school-going kids, and mothers who happen to be housewives only. In comparison to the food secure households, more of the households with food insecurity have been living below poverty line $(59.5 \%)$ with $7.8 \%$ being classified as households that are hard-core poor. The percentage of households with food insecurity in Malaysia is higher in urban low-income households, such as 66.6\% (Zalilah 1998) and 65.7\% (Zalilah and Ang 2001) compared to rural low-income households 58\% (Shariff and Khor 2008). Nevertheless, the quantity of urban low-income households facing child hunger (27.8\% and $27.1 \%)$ are lower compared to rural households $(34.5 \%)$.

Therefore, to achieve Vision 2020 and the targets of Malaysian National Plans regarding food security, socioeconomic development and poverty alleviation at the grass-root level, it is very important to study the current situation of household food security among different economic groups. This study is an attempt to measure and analyze the level of household food insecurity of some selected households of the low income people in the East Coast Economic Region of the country.

\section{Data, Model, and Methodology}

\section{Measurement of the Household Food Security}

There are several ways to measure household food security condition, such as individual food intake (dietary intake), household calorie acquisition, dietary diversity, and indices of household coping strategies. Household food security also can be assessed using direct and indirect measurements. Food Sufficiency Status Question (Briefel et al. 1992), Community Childhood Hunger Identification Project Instrument (Wehler et al. 1994), Radimer/Cornell Hunger and Food Insecurity Instrument (Radimer et al. 1992), Cumulative Food Security 
Index (Maxwell 1996), Food Security Core Model (Bickel et al. 2000), and Household Food Insecurity Access Scale (Coates et al. 2007) are among questionnaire-based techniques designed to directly measure core behaviors and experiences related to food sufficiency or access or food insecurity. These techniques and measurements have been applied by the person most responsible for food and food provision in households. The indirect measures of food insecurity are utilization of food security-related programs, income-based measurements of poverty, anthropometric measures, financial hardship indicators, dietary intake and other nutrition and health parameters. They reveal the vulnerability level in which food insecurity may be deduced reasonably (Radimer et al. 1990; Office of Nutrition Policy and Promotion at Health Canada 2002). This study measures household food security by directly using the questionnaire-based techniques developed by Coates et al. (2007) for USAID.

USAID's Food and Nutrition Technical Assistance (FANTA) project has supported a series of research initiatives. These initiatives are to explore and test different options for meeting the need for relatively simple, but methodologically rigorous indicators of the access component of household food insecurity for the USAID Title II, Child Survival, and Health Grant programs. Finally they have developed the method of measuring Household Food Insecurity Access (HFIA) Related Condition. This is based on the idea that the experience of food insecurity (access) cause predictable reactions and responses that can be captured, quantified, and summarized through a survey on a scale based on the following nine questions.

Q1 Did you have sufficient food for your family in the last four weeks?

Q2 Were you able to eat the food you prefer in the last four weeks?

Q3 Could you afford some variety of food items for your family without a single monotonous item in the last four weeks?

Q4 Did you have to eat some kind of food that you did not want to in the last four weeks?

Q5 Did all of your family members had enough food for themselves in the last four weeks?

Q6 Did any of your family members had to skip a meal in any day due to food shortage in the last four weeks?

Q7 For any day, did you have any situation where there was no food for anybody in the family in the last four weeks?

Q8 Did any member of your family had to go to bed without eating dinner in the last four weeks?

Q9 Did any of your family members passed a whole day (24 hours) with no food at all in the last four weeks?

The intensities of the occurrence of these 9 questions are also measured in three frequencies - rarely (1-2 times per month) or sometimes (3-10 times) or often (10+ times per month) - which indicate by Q1a to Q9a. Based on the answers of these nine queries, Household Food Insecurity Access (HFIA) Prevalence is calculated for each household by assigning a code ranging from 1 to 4, where 1=Food Secure, 2=Mildly Food Insecure Access, 3=Moderately Food Insecure Access, 4=Severely Food Insecure Access. The four food security categories are created sequentially, in the same order as shown Equations 1 through 4 , to ensure that every household are placed in a single, unique category and is classified according to their most severe response. The measurements of the categories are as follows:

- Category = 1 if $[(\mathrm{Q} 1=0$ or $\mathrm{Q} 1=1)$ and $\mathrm{Q} 2=0$ and $\mathrm{Q} 3=0$ and $\mathrm{Q} 4=0$ 
and $\mathrm{Q} 5=0$ and $\mathrm{Q} 6=0$ and $\mathrm{Q} 7=0$ and $\mathrm{Q} 8=0$ and $\mathrm{Q} 9=0]$

- Category $=2$ if $[(\mathrm{Q} 1 \mathrm{a}=2$ or $\mathrm{Q} 1 \mathrm{a}=3$ or $\mathrm{Q} 2 \mathrm{a}=1$ or $\mathrm{Q} 2 \mathrm{a}=2$ or $\mathrm{Q} 2 \mathrm{a}=3$ or

$\mathrm{Q} 3 \mathrm{a}=1$ or $\mathrm{Q} 4 \mathrm{a}=1$ ) and $\mathrm{Q} 5=0$ and $\mathrm{Q} 6=0$ and $\mathrm{Q} 7=0$ and

$\mathrm{Q} 8=0$ and $\mathrm{Q} 9=0]$

- Category $=3$ if $[(\mathrm{Q} 3 \mathrm{a}=2$ or $\mathrm{Q} 3 \mathrm{a}=3$ or $\mathrm{Q} 4 \mathrm{a}=2$ or $\mathrm{Q} 4 \mathrm{a}=3$ or $\mathrm{Q} 5 \mathrm{a}=1$ or

$\mathrm{Q} 5 \mathrm{a}=2$ or $\mathrm{Q} 6 \mathrm{a}=1$ or $\mathrm{Q} 6 \mathrm{a}=2$ ) and $\mathrm{Q} 7=0$ and $\mathrm{Q} 8=0$ and $\mathrm{Q} 9=0]$

- Category $=4$ if $[\mathrm{Q} 5 \mathrm{a}=3$ or $\mathrm{Q} 6 \mathrm{a}=3$ or $\mathrm{Q} 7 \mathrm{a}=1$ or $\mathrm{Q} 7 \mathrm{a}=2$ or $\mathrm{Q} 7 \mathrm{a}=3$ or $\mathrm{Q} 8 \mathrm{a}=1$ or $\mathrm{Q} 8 \mathrm{a}=2$ or $\mathrm{Q} 8 \mathrm{a}=3$ or $\mathrm{Q} 9 \mathrm{a}=1$ or $\mathrm{Q} 9 \mathrm{a}=2$ or $\mathrm{Q} 9 \mathrm{a}=3]$

Further, the findings of the nine indicators of Household Food Insecurity Access (HFIA) are categorized into three domains, which are measured by the following domains:

- Anxiety and uncertainty domain is measured when households respond "yes" to Q1.

- Insufficient food quality domain is measured when households respond "yes" to Q2 or Q3 or Q4.

- Insufficient food intake and its physical consequences domain are measured when households respond “yes” to Q5 or Q6 or Q7 or Q8 or Q9.

Further, this study measures the HFIA Scale Score which is considered as a continuous measure of the degree of food insecurity (access) in households. HFIA Scale Score is calculated by providing value for each household. The frequency of occurring value are given as 1,2,3 and the value for relevant question was put as 0 if the answer is "No", such as if $\mathrm{Q} 1=0$ then $\mathrm{Q} 1 \mathrm{a}=0$, if $\mathrm{Q} 2=0$ then $\mathrm{Q} 2 \mathrm{a}=0$, etc. Therefore, the range of minimum to maximum score for a household is $0-27$. The higher the score is, the higher the level of food insecurity (access) is, and the lower the score is, the lesser the level of food insecurity (access) is.

Finally, this study also analyzes the distribution of HFIA Prevalence in Malaysia based on location and poverty levels.

\section{Statistical Analysis}

To check the robustness of the results, several statistical tests have been carried out. Whether there is any statistically significant difference among the frequency of the four categories of households, this study also conducts a Single Sample Chi Square Test on HFIA Prevalence.

Further to verify the validity of the HFIA Prevalence, this study carries out $R A S C H$ Measurement Model. The RASCH measurement model is used by the US Department of Agriculture (USDA) to measure the household food security (Bickel et al. 2000). The RASCH measurement model assumes an underlying continuum (for this study, the severity of food insecurity experienced by the household) upon which both items and households can be located, and assumes that the probability of a household affirming a specific item depends on the relative severity of the household and the item. The RASCH model assumes specifically that the log of the odds of a household affirming an item is proportional to the difference between the severity level of the household and the severity level of the item. Here, a household that has not experienced any of the conditions of food insecurity covered by the survey questions, is assigned a scale value of 0 , while a household that has experienced all of them has a scale value of 9 . 
To check the sensitivity, this study employs Monte Carlo (MC) simulation on the HFIA Scale Score. Generally, it is impossible to find out the actual value but based on past experiences or experts in this field, or historical data, it is possible to estimate a figure. Although the estimate is derived from the field survey sample data, it has several inherent risk and uncertainty as it is an estimated value of an unknown population. MC simulation technique is utilized to show how the sample data vary from real life's uncertain situations. This technique offers the decision-maker with many possible results from the most conservative viewpoint to the most liberal viewpoint and the possibilities that it will take place given a method of action. It has several advantages over the "single-point estimate" or deterministic analysis. MC technique is a stochastic method using random numbers having different values with corresponding probabilities to examine the issues in question. The MC simulation analyses by designing models with potential outcomes by replacing a set of values from the distribution of the probability input. Then, it measures the results repeatedly, every time with a different group of random values from the probable inputs. MC simulation can provide thousands of possibilities before it is done dependently on specified ranges and numbers of uncertainties. If a model is done according to estimated ranges, the model's output will also be in a range. Based on this, the MC simulation offers a more comprehensive observation of what might occur by producing possible outcome values of the distributions. It not only reveals what can take place, but also the possibility that what may occur. The MC simulation's accuracy is a function of the quantity of trails which means the results' confidence bounds can be computed readily according to the quantity of trails.

To see if there is any statistically significant difference among area, location, and poverty level based on the frequency of the four categories of household food security, this study uses the Tukey's HSD (honest significant difference) Test as well as the Scheffé's method. Tukey method is preferable when considers pairwise comparisons, and Scheffé method is preferable when many or all contrasts are taken into consideration. Scheffé's method is generally too conservative to produce experimental error rate to be smaller than $\alpha$.

\section{Data Collection}

For the empirical assessment, this study mostly relies on primary data that have been collected through an extensive questionnaire survey at household level in the East Coast Economic Region (ECER) in Malaysia. ECER is more than half of the Peninsular Malaysia with an area of about 66,000 square kilometers that covers the states of Kelantan, Terengganu, Pahang, and the district of Mersing in Johor. ECER is very crucial for two major reasons (Alam et al. 2012b): (a) it is the most vulnerable area in Malaysia due to climate changes and (b) the income level of this region is low and poverty rate is high, which is a hindrance to achieving Vision 2020 in Malaysia.

This study collected primary data from 460 households from the urban and rural areas of ECER. The urban area of Kuantan and rural area of Pekan were selected from the Pahang state. The urban area of Kota Bharu and rural area of Tumpat were selected from the Kelantan state. The urban area of Kuala Terengganu and rural area of Marang were chosen from the Terengganu state. A questionnaire guide technique was used to collect data. The survey was conducted by the regular remunerators of the Implementation Coordination Unit (ICU) agency in the months of July-October, 2012. The samples were taken from the E-Kasih poor household database. E-Kasih system is an integrated database system that enlists poor households at national level to plan, implement, and monitor poverty programs in Malaysia. 
The study followed the cluster random sampling technique. Initially, the samples were clustered by location and then by poverty category. Finally, from each category, samples were picked randomly. Based on the formula of required size of samples (Yamane 1967: 886), first, a sample of 400 households were selected according to the proportion of population distribution. However, to ensure a good number of observations for each group, which was needed for sound statistical analysis for any particular group, another 100 households were added to the list. However, while targeting 500, after collecting and validating the data, finally, 460 households were considered for the study. The final distribution of the collected sample is given in the Table 1.

Table 1 Distribution of the Sample of the Study

\begin{tabular}{rrrrrrrrrr}
\hline & \multicolumn{2}{c}{ Pahang } & \multicolumn{2}{c}{ Kelantan } & \multicolumn{2}{c}{ Terengganu } & \multicolumn{2}{c}{ Total } & \multicolumn{2}{c}{ All } \\
& Urban & Rural & Urban & Rural & Urban & Rural & Urban & Rural & Total \\
\hline \hline Hard core Poor & 2 & 15 & 33 & 22 & 6 & 32 & 41 & 69 & 110 \\
Poor & 12 & 14 & 21 & 34 & 27 & 46 & 60 & 94 & 154 \\
$\begin{array}{r}\text { Recently Marginally } \\
\text { Non-poor }\end{array}$ & 11 & 9 & 15 & 16 & 4 & 16 & 30 & 41 & 71 \\
$\begin{array}{r}\text { Marginally Non- } \\
\text { poor }\end{array}$ & 18 & 30 & 32 & 25 & 4 & 16 & 54 & 71 & 125 \\
\hline Total Target Group & 43 & 68 & 101 & 97 & 41 & 110 & 185 & 275 & 460 \\
\hline State Total & & 111 & & 198 & & 151 & & 460 & \\
\hline
\end{tabular}

* In the E-Kasih system, the rural poverty data were categorized as monthly income per person up to RM110 is hard-core poor, up to RM185 is poor, and up to RM227 is marginally non-poor, and for urban area up to RM120 is hard-core poor, up to RM200 is poor, and up to RM340 is marginally nonpoor.

\section{Analysis and Discussions}

\section{Household Food Availability}

Beyond the measurement of household food security according to the USAID's measurement of HFIA, initially this study asked households about their food status in five categories (Table 2). Only $14.8 \%$ said that they had enough of the food that they would like, but majority $(41.1 \%)$ of the households mentioned that they never had enough of the kind of food they would need. Only $9.1 \%$ of the households mentioned that they frequently stayed hungry. This measurement was based on the direct perception of the household, where USAID's measurement of HFIA were based on the frequency calculation.

Table 2 Family Food Status in Last One Month

\begin{tabular}{lcc}
\hline Food Status in the Family & No of Households & \% of Total \\
\hline \hline Enough of the kinds of food you want to eat & 68 & $14.8 \%$ \\
Enough but not always the kinds of food you want & 189 & $41.1 \%$ \\
Sometimes not enough to eat & 100 & $21.7 \%$ \\
Often not enough to eat & 61 & $13.3 \%$
\end{tabular}




\begin{tabular}{lrr} 
Frequently stay hungry & 42 & $9.1 \%$ \\
\hline Total & 460 & $100 \%$ \\
\hline
\end{tabular}

\section{Household Food Insecurity Access Related Condition}

The nine indicators provide specific and disaggregated information about the behaviors and perceptions of the surveyed households (Table 3). Percentile analysis of these indicators measures household condition at any level of severity. By considering personal experiences with uncertainty and anxiety about acquiring food during the previous month, 69.8\% households are somehow worried about food. Among them, 33.3\% are often worried about food. In the survey area, among the households, 52.8\% mentioned that they never face the problem having access to the kind of food they would prefer, whereas $29.3 \%$ have often been unable to eat their preferred food.

While asking about dietary choices related to variety, $60 \%$ of the households mention that they never have to eat an undesired monotonous diet like little diversity in the different types of foods consumed, but $17 \%$ often eat just a few kinds of food. Further looking at the dimension of limited choices, $32.8 \%$ households mention that they have to eat food that they find socially or personally undesirable due to a lack of resources.

Table 3 Frequency of Household Food Insecurity Access Scale

\begin{tabular}{lrrrr}
\hline HFIA Scale Measurement Issues & Never & $\begin{array}{c}\text { Rarely (1-2 } \\
\text { times per } \\
\text { month) }\end{array}$ & $\begin{array}{c}\text { Sometimes } \\
(3-10 \text { times })\end{array}$ & $\begin{array}{c}\text { Often (10+ } \\
\text { times per } \\
\text { month) }\end{array}$ \\
\hline \hline Worry about food & $139(30.2 \%)$ & $104(22.6 \%)$ & $64(13.9 \%)$ & $153(33.3 \%)$ \\
Unable to eat preferred food & $243(52.8 \%)$ & $25(5.4 \%)$ & $57(12.4 \%)$ & $135(29.3 \%)$ \\
Eat just a few kinds of foods & $276(60 \%)$ & $74(16.1 \%)$ & $30(6.5 \%)$ & $80(17.4 \%)$ \\
Eat foods they really do not want to eat & $309(67.2 \%)$ & $41(8.9 \%)$ & $40(8.7 \%)$ & $70(15.2 \%)$ \\
Eat a smaller meal & $382(83 \%)$ & $16(3.5 \%)$ & $20(4.3 \%)$ & $42(9.1 \%)$ \\
Eat fewer meals in a day & $402(87.4 \%)$ & $8(1.7 \%)$ & $14(3 \%)$ & $36(7.8 \%)$ \\
No food of any kinds in the household & $418(90.9 \%)$ & $8(1.7 \%)$ & $29(6.3 \%)$ & $5(1.1 \%)$ \\
Go to sleep hungry & $435(94.6 \%)$ & $25(5.4 \%)$ & $0(0 \%)$ & $0(0 \%)$ \\
Go the whole day and night without eating & $446(97 \%)$ & $14(3 \%)$ & $0(0 \%)$ & $0(0 \%)$ \\
\hline
\end{tabular}

While asking about eating smaller amount of food due to lack of resources, $17 \%$ households say, "yes", and $9.1 \%$ of them suffer from it often. However, $12.5 \%$ skip a regular meal due to lack of food, and $7.8 \%$ of them do it often.

Only $9.1 \%$ of the households face the situation where the households have no food of any kind to eat because in this situation, food is not available to household members through the usual means (e.g. through purchase, from the garden or field, from storage, etc.), and the frequency for $6.3 \%$ of them, it happens sometimes in a month. Moreover, 5.4\% of them also go to sleep hungry 1-2 times in a month, and 3\% of them do not eat from the time they awake in the morning to the time they awake the next morning due to lack of food.

\section{Household Food Insecurity Access Prevalence}

Based on the HFIA prevalence, households can be categorized into four levels of food insecurity (access). If households response more affirmatively, they are categorized as 
increasingly food insecure. Table 4 illustrates the categorizations, where every household is placed in a single unique category based on the set of responses.

Table 4 Measurement of Household Food Insecurity Access Scale Score

\begin{tabular}{|c|c|c|c|c|}
\hline \multirow{2}{*}{\multicolumn{2}{|c|}{ HFIAS Measurement Issues }} & \multicolumn{3}{|c|}{ Category of food insecurity (access) } \\
\hline & & $\begin{array}{l}\text { 1-2 times } \\
\text { lonth) }\end{array}$ & $\begin{array}{c}\text { Sometimes } \\
\text { (3-10 times) }\end{array}$ & $\begin{array}{l}\text { Often }(10+\text { times } \\
\text { per month })\end{array}$ \\
\hline \multicolumn{5}{|l|}{ Worry about food } \\
\hline \multicolumn{5}{|c|}{ Unable to eat prefer food } \\
\hline \multicolumn{5}{|c|}{ Eat just a few kinds of foods } \\
\hline \multicolumn{5}{|c|}{ Eat foods they really do not want eat } \\
\hline \multicolumn{5}{|l|}{ Eat a smaller meal } \\
\hline \multicolumn{5}{|c|}{ Eat fewer meals in a day } \\
\hline \multicolumn{5}{|c|}{ No food of any kinds in the household } \\
\hline \multicolumn{5}{|l|}{ Go to sleep hungry } \\
\hline \multicolumn{5}{|c|}{ Go to whole day and night without eating } \\
\hline \multicolumn{5}{|c|}{ Legend of the illustration used in the Table 4} \\
\hline 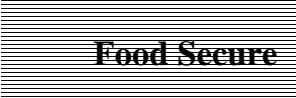 & \multicolumn{3}{|c|}{$\begin{array}{l}\text { Moderately Food } \\
\text { Insecure }\end{array}$} & $\begin{array}{l}\text { Severely Hod } \\
\text { Insecune }\end{array}$ \\
\hline
\end{tabular}

Source: Coates et al. 2007

In Table 5, the four categories of household food security are created sequentially based on Equations 1-4 and as illustrated in Table 4. Based on the survey, this study finds $52.8 \%$ of the households are under the category of "food secure." These households experience none of the food insecurity (access) conditions or just rarely experience worry. Among the surveyed households, $23.3 \%$ face mild food insecurity (access) who are worried about not having enough food sometimes or often, and/or unable to eat preferred food, and/or rarely eat a more monotonous diet than desired and/or also rarely eat some undesirable food.

Table 5 Distribution of Household Food Insecurity Access 


\begin{tabular}{lcc}
\hline \multicolumn{1}{c}{ HFIA Category } & HFIA Prevalence & \% of HFIA Prevalence \\
\hline \hline 1= Food secure & 243 & $52.8 \%$ \\
2= Mildly Food Insecure Access & 107 & $23.3 \%$ \\
3= Moderately Food Insecure Access & 66 & $14.3 \%$ \\
4= Severely Food Insecure Access & 44 & $9.6 \%$ \\
\hline Total & 460 & $100.0 \%$ \\
\hline
\end{tabular}

Among the households, $14.3 \%$ are moderately food insecure. These households frequently sacrifice quality of food by eating a monotonous diet or undesirable food sometimes or often, and/or rarely or sometimes reduce eating the quantity of food. There are $9.6 \%$ of households that are severely food insecure who have had to often cut back on their meal size or frequency of meals, and/or have experienced any of the three most severe conditions such as going to bed hungry, running out of food infrequently, rarely or at least once in the past month not eating the whole day and night.

The value of Single Sample Chi-square test is 207.7. The Chi-square test shows that the frequencies of the four categories are significantly different at $1 \%$ level. It indicates that the number of food secure households significantly differs from other food insecure households.

To check the validity of the four categories of household food security that are measured by the logical indications given by USAID, this study uses the RASCH measurement model. Here, the household which has faced any of the food insecurity conditions provided in the survey questionnaire is given the scale value of 0 , whereas a household which has faced all of the food insecurity conditions is given the scale value of 9 . According to the related severity of the household and the items, the household food security categories are given in Table 6.

Table 6 RASCH Validation Test for Household Food Security Category

\begin{tabular}{|c|c|c|c|c|c|c|}
\hline $\begin{array}{c}\text { Number of } \\
\text { Total } \\
\text { Affirmative } \\
\text { Response }\end{array}$ & $\begin{array}{l}\text { Number of } \\
\text { Households }\end{array}$ & $\begin{array}{c}\text { Item } \\
\text { Measure* }\end{array}$ & $\begin{array}{l}\text { Number of } \\
\text { Household in } \\
\text { each category }\end{array}$ & $\begin{array}{c}\% \text { of } \\
\text { Households }\end{array}$ & Code & Category \\
\hline 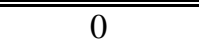 & $\overline{l 139}$ & "-- & \multirow{3}{*}{268} & \multirow{3}{*}{$58.3 \%$} & \multirow{3}{*}{1} & \multirow{3}{*}{ Food secure } \\
\hline 1 & 104 & -5.04 & & & & \\
\hline 2 & 25 & -5.04 & & & & \\
\hline 3 & 49 & -1.63 & 49 & $10.7 \%$ & 2 & $\begin{array}{l}\text { Mildly Food } \\
\text { Insecure Access }\end{array}$ \\
\hline 4 & 65 & 1.63 & 65 & $14.1 \%$ & 3 & $\begin{array}{l}\text { Moderately Food } \\
\text { Insecure Access }\end{array}$ \\
\hline 5 & 20 & 5.04 & \multirow{5}{*}{78} & \multirow{5}{*}{$16.9 \%$} & \multirow{5}{*}{4} & \multirow{5}{*}{$\begin{array}{l}\text { Severely Food } \\
\text { Insecure Access }\end{array}$} \\
\hline 6 & 16 & 5.04 & & & & \\
\hline 7 & 17 & 5.04 & & & & \\
\hline 8 & 11 & 5.04 & & & & \\
\hline 9 & 14 & 5.04 & & & & \\
\hline
\end{tabular}

The RASCH model also statistically groups data into four categories, but the number of households for each category differs from the USAID's measurement of HFIA (Table 6). RASCH shows more households in two extreme categories and less in the two middle categories. RASCH categorizes $58.3 \%$ households as food secure and $16.9 \%$ as severely food 
insecure. USAID's measurement of HFIA logically categorizes the indicators in a similar group by looking at the frequency of the occurrence, whereas RASCH categorizes the indicators in a similar group based on the probability of data homogeneity. Thus, USAID's measurement of HFIA is theoretically more preferable, and this study considers the findings of USAID's measurement of HFIA.

\section{Household Food Insecurity Access Related Domains}

The findings of the nine indicators of Household Food Insecurity Access (HFIA) are categorized as three domains. Among them, $69.8 \%$ of the households are found under this anxiety and uncertainty domain, $47.2 \%$ of them are under insufficient food quality domain, and $17 \%$ of the households are under insufficient food intake and its physical consequences domain.

\section{Household Food Insecurity Access Scale Score}

The total HFIA Scale Score is 5.18 from the surveyed households, which indicates an overall lower level of food insecurity (access) of a household. To check the sensitivity of the data, this study performs 10,000 trails for Monte Carlo simulation for the HFIA Scale Score. Since the data range is positive (0-27), it ran one tailed simulation only. The simulation assumes normal distribution of data and finds mean 6.82 and standard deviation is 4.88 , whereas the actual sample mean is 5.18 and standard deviation is 6.46 . The skewness value for simulation model is 0.8 (Figure 2) whereas for the sample is 1.3 (Figure 3) which indicates both are positively skewed.

Figure 2 Frequency Distribution of HFIA Scale Score

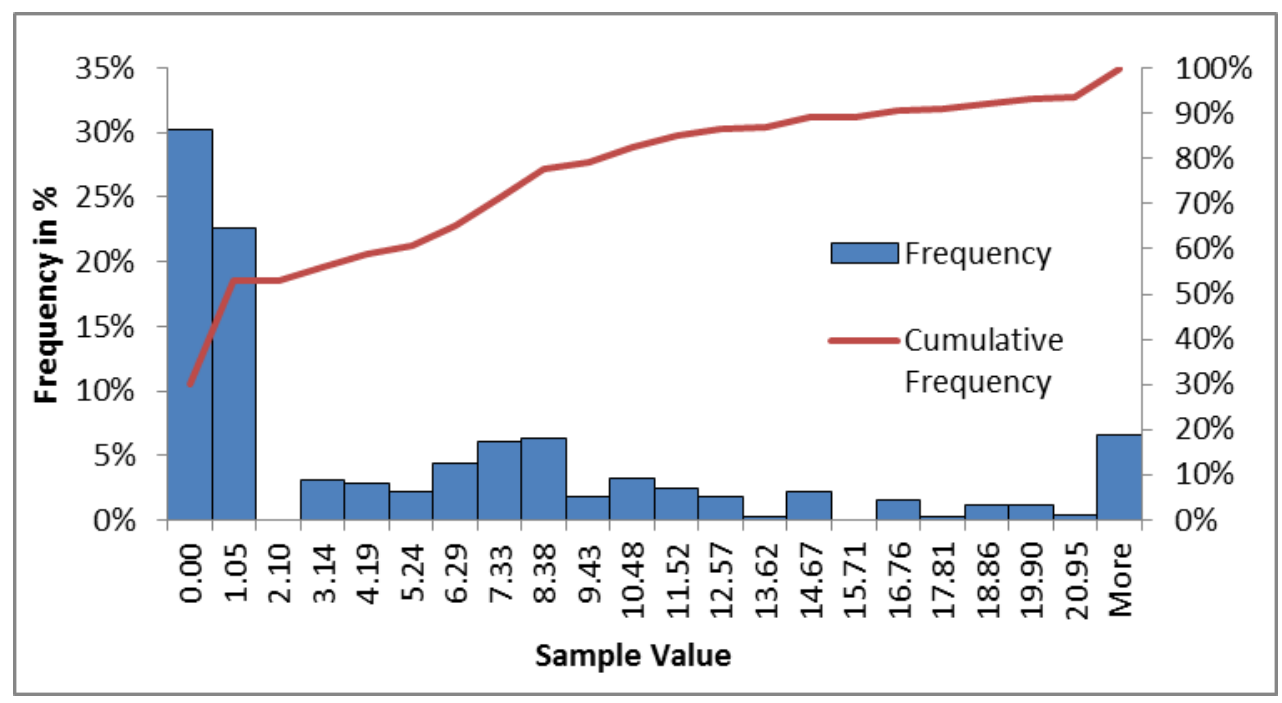

Figure 3 Frequency Distribution for Simulated HFIA Scale Score 


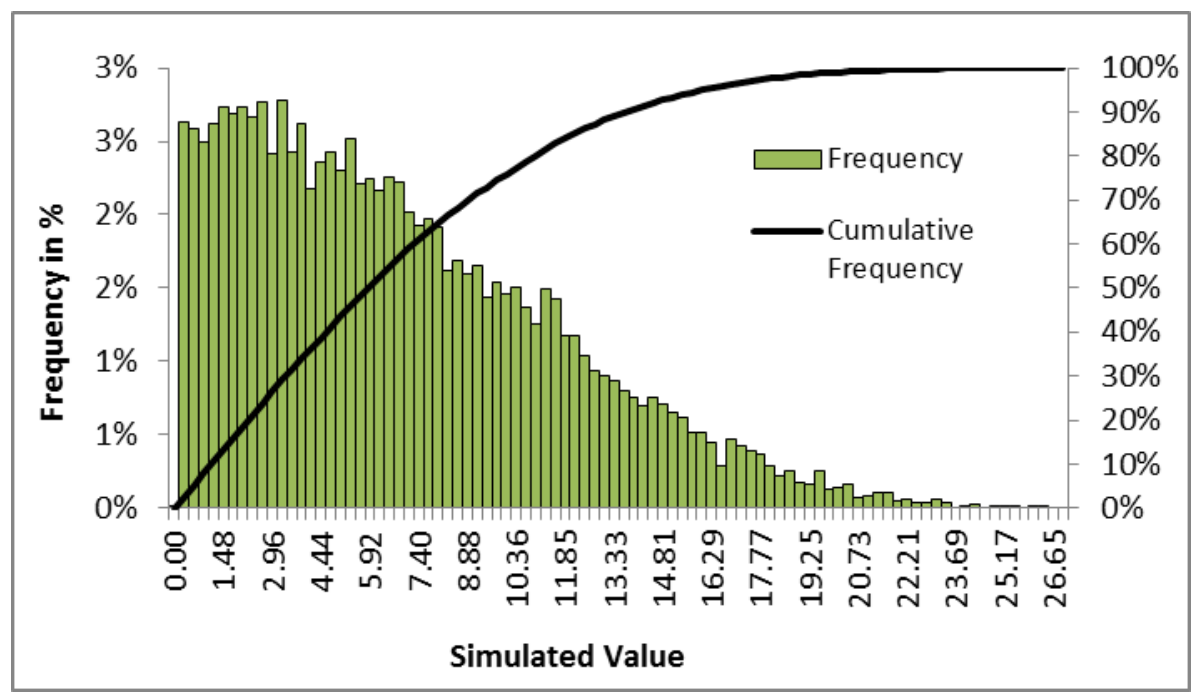

Based on one tailed analysis, the simulated value of the score can optimally reach the maximum value of 26.98 and minimum value of 0.0003 . There are around $50 \%$ chances that the mean value would be 6.82 , and at $95 \%$ confidence level, the mean interval will be between 6.72 and 6.91 . However, there is a $10 \%$ chance that the value would be up to 1.14 as well as more than 13.80 . There is a $25 \%$ chance that the value would be up to 2.94 as well as more than 10 (Table 7).

Table 7 Simulated Value for Uncertainty of HFIA Scale Score

\begin{tabular}{cc}
\hline Percentiles & Simulation Value \\
\hline $1 \%$ & 0.00 \\
$5 \%$ & 0.59 \\
$10 \%$ & 1.14 \\
$25 \%$ & 2.94 \\
$75 \%$ & 10.00 \\
$90 \%$ & 13.80 \\
$95 \%$ & 16.15 \\
$99 \%$ & 20.40 \\
\hline
\end{tabular}

\section{Locational Distribution of Household Food Security}

According to the statistical test of Tukey's HSD and Scheffé, there is no significant difference available in the level of household food security due to the urban or rural area or state wise locational differences among the three states of Malaysia. However, the percentile analysis shows urban area is more food secure than the rural area. In the urban area, food security is $56.2 \%$ of the households and in rural area it is $50.5 \%$ (Table 8). Urban area is more food secure in Kelantan and Terengganu but in Pahang there is no difference between urban and rural areas. Among the states, the urban area of Kelantan is more food secure compared to Pahang and Terengganu, but the rural area of Pahang is more food secure compared to Kelantan and Terengganu. The rural areas are also more severely food insecure compared to urban areas. Among the rural areas, Terengganu is more severely food insecure compared to Pahang and Kelantan.

Table 8 Location wise Distribution of Household Food Security 


\begin{tabular}{|c|c|c|c|c|c|c|}
\hline \multirow{2}{*}{ States } & \multirow{2}{*}{ Location } & \multicolumn{4}{|c|}{ Level of Food Security } & \multirow{2}{*}{ Total } \\
\hline & & 1 & 2 & 3 & 4 & \\
\hline \multirow[t]{2}{*}{ Kelantan } & Rural & $46(47 \%)$ & $25(26 \%)$ & $16(17 \%)$ & $10(10 \%)$ & 97 \\
\hline & Urban & $59(58 \%)$ & $18(18 \%)$ & $15(15 \%)$ & $9(9 \%)$ & 101 \\
\hline \multirow[t]{2}{*}{ Pahang } & Rural & $37(54 \%)$ & $16(24 \%)$ & $9(13 \%)$ & $6(9 \%)$ & 68 \\
\hline & Urban & $23(54 \%)$ & $10(23 \%)$ & $6(14 \%)$ & $4(9 \%)$ & 43 \\
\hline \multirow[t]{2}{*}{ Terengganu } & Rural & $56(51 \%)$ & $27(25 \%)$ & $15(14 \%)$ & $12(11 \%)$ & 110 \\
\hline & Urban & $22(54 \%)$ & $11(27 \%)$ & $5(12 \%)$ & $3(7 \%)$ & 41 \\
\hline \multicolumn{2}{|c|}{ Urban Total } & $104(56.2 \%)$ & $39(21.1 \%)$ & $26(14.1 \%)$ & $16(8.6 \%)$ & $185(40.2 \%)$ \\
\hline \multicolumn{2}{|c|}{ Rural Total } & $139(50.5 \%)$ & $68(24.7 \%)$ & $40(14.5 \%)$ & $28(10.2 \%)$ & $275(59.8 \%)$ \\
\hline \multicolumn{2}{|c|}{ Grand Total } & $243(52.8 \%)$ & $107(23.3 \%)$ & $66(14.3 \%)$ & $44(9.6 \%)$ & $460(100 \%)$ \\
\hline \multicolumn{7}{|c|}{$\begin{array}{l}\text { 1= Food Secure, } 2=\text { Mildly Food Insecure, } 3=\text { Moderately Food Insecure, } 4=\text { Severely Food } \\
\text { Insecure }\end{array}$} \\
\hline
\end{tabular}

\section{Poverty Status and Household Food Security}

There are interesting relationships between poverty status and food security status of households (Table 9). According to the statistical test of Tukey's HSD and Scheffé, there are significant differences available in the level of household food security due to the poverty status of the households. This is found only for the marginally non-poor group, who significantly differs with all other categories. Interestingly, the level of household food security of recently marginally non-poor group does not statistically significantly differ with other poor groups except the marginally non-poor group.

Among the hard core poor, 38\% are food secure but among the non-poor, 36-38\% households are not food secure. The normal poor are more mildly food insecure than the nonpoor, even more than the hard core poor. The hard core poor suffers from food insecurity more moderately and severely compared to the poor and non-poor. Among the non-poor, 2\% of recently out of poverty households suffer more food insecurity moderately compared to the existing non-poor. Among all of the non-poor households, $4 \%$ are still suffering severely from food insecurity.

Table 9 Poverty Status wise Distribution of Household Food Security

\begin{tabular}{lccccc}
\hline \multirow{2}{*}{ Poverty Status } & \multicolumn{3}{c}{ Level of Food Security } & \multirow{2}{*}{ Total } \\
\cline { 2 - 5 } & $\mathbf{1}$ & $\mathbf{2}$ & $\mathbf{3}$ & $\mathbf{4}$ & \multicolumn{1}{c}{$110(23.9 \%)$} \\
Hard core poor & $42(38 \%)$ & $24(22 \%)$ & $26(24 \%)$ & $18(16 \%)$ & $154(33.5 \%)$ \\
Poor & $77(50 \%)$ & $44(29 \%)$ & $15(10 \%)$ & $18(12 \%)$ & $15 \%$ \\
Recently Marginally Non-poor & $44(62 \%)$ & $14(20 \%)$ & $10(14 \%)$ & $3(4 \%)$ & $71(15.4 \%)$ \\
Marginally Non-poor & $80(64 \%)$ & $25(20 \%)$ & $15(12 \%)$ & $5(4 \%)$ & $125(27.2 \%)$ \\
\hline Total & $243(53 \%)$ & $107(23 \%)$ & $66(14 \%)$ & $44(10 \%)$ & $460(100 \%)$ \\
\hline
\end{tabular}

1= Food Secure, 2= Mildly Food Insecure, 3= Moderately Food Insecure, 4= Severely Food Insecure 


\section{Conclusions and Recommendations}

In case of Malaysia, the phrase "food security" still carries the meaning as "food availability" and that mostly indicates for the crop of rice. As a result, government strategies largely fail to serve the intended objective of lowering the households' food insecurity. To achieve Vision 2020 and food security at grass-roots level, here the issue needs to be understood based not only on who are food insecure at present and why so are they, but also on who might become food insecure in the future and why this would happen to them.

Therefore, this study measures the status of household food security in Malaysia. It finds that the majority of the households belonging to the poor and hard core poor groups are food insecure. But more than one third of the households in the non-poor low income group are also food insecure. The whole ECER area has the similar nature of food security level that ranges from $52 \%$ to $54 \%$. On the whole, $52.8 \%$ of households are fully food secure (access), but $23.3 \%$ of households are facing some amount of food insecurity, $14.3 \%$ face moderate food insecurity, and $9.6 \%$ are severely food insecure.

Government is a major player who should play a key role in controlling the threats of food insecurity via budgets, policies, and by having a legislative guideline for efforts on adaptation by other interested parties. The government of Malaysia is already working to eradicate poverty, but here, more attention is deserved by those who are food insecured, but not under the poverty line. These people are marginally out of poverty but still vulnerable for food insecurity. At the same time, special care is essential for those who are severely food insecured. Moreover, finding out the reasons of household food security is also very important for developing appropriate mitigation and adaptation options. There are several socioeconomic as well as natural, environmental, and ecological factors that are also responsible for the food insecurity. As there has been no massive long-term food insecurity in Malaysia at macro level, most of the food insecurity happens at household level due to the seasonal or short term events like floods, droughts, etc. Therefore, involvements of other nongovernmental organizations, international agencies, and similar stakeholders are also important for the sustainable household food security.

Community-based organizations (CBOs) in risk management, particularly in the emergency times, are well acknowledged and linked to the entire food security process. Relying on the social capital, CBOs can help poor and low-income Malaysian households in controlling and coping with risks as well as preventing risks, such as co-sponsoring of local plans for infrastructure development. Private sector can ensure availability of food during the times of shortfall in production, and availability of inputs from agriculture as well as provide credit against labor, harvests, etc. Banks and insurance organizations can offer different savings, credit facilities, and insurance schemes to seasonally food insecure groups.

\section{Acknowledgement}

We are thankful to Ministry of Science, Technology and Environment of the Government of Malaysia for generously funding the research, under the Research University Grant Project UKM-GUP-PI-08-34-081 and FRGS/1/2012/SS07/UKM/01/3.

\section{References}


Alam, M.M., Morshed, G., Siwar, C. \& Murad, M.W. 2012b. Initiatives and Challenges of Agricultural Crop Sector in ECER Development Projects in Malaysia, AmericanEurasian Journal of Agricultural \& Environmental Science 12(7): 922-931.

Alam, M.M., Siwar, C., Mohd Ekhwan, T., Molla, R.I. \& Talib, B., 2012a. Climate Change Induced Adaptation by Paddy Farmers in Malaysia, Mitigation and Adaptation for Global Change 17(2): 173-186.

Alam, M.M., Siwar, C., Murad, M.W. \& Mohd Ekhwan, T. 2011. Farm Level Assessment of Climate Change, Agriculture and Food Security Issues in Malaysia, World Applied Sciences Journal 14(3): 431-442.

Bickel, G., Nord, M., Price, C., Hamilton, W. \& Cook, J. 2000. Guide to measuring household food security, revised 2000. Alexandria VA: US Department of Agriculture, Food and Nutrition Service.

Briefel, R.R \& Woteki, C.E. 1992. Development of food sufficiency questions for third national health and nutrition examination survey. Journal of Nutrition Education 24: 24-28.

Coates, J., Swindale, A. \& Bilinsky, P. 2007. Household food insecurity access scale (HFIAS) for measurement of household food access: indicator guide. Washington DC: Food and Nutrition Technical Assistance Project, Academy for Educational Development.

FAO. 2003. Trade reforms and Food security: Conceptualizing the Linkages. Rome: FAO.

Maxwell, D.G. 1996. Measuring food insecurity: The frequency and severity of coping strategies. Food Policy 21: 291-303.

Office of Nutrition Policy and Promotion at Health Canada. 2002. Discussion paper on household and individual food insecurity (online). http://www.hc-sc.gc.ca/fnan/nutrition/pol/food_sec_entire-sec_aliments_entier-eng.php [14 April 2015].

Parke, E.W., Nord, M. \& Zager, R.E. 2010. In longitudinal data from the survey of Program Dynamics, $16.9 \%$ of the U.S. population was exposed to household food insecurity in a five-year period. Journal of Hunger and Environmental Nutrition 5(3): 380-398.

Radimer, K.L., Olson, C.M. \& Campbell, C.C. 1990. Development of indicators to assess hunger. Journal of Nutrition 129: 1544-1548.

Radimer, K.L., Olson, C.M., Greene, J.C., Campbell, C.C. \& Habicht, J.P. 1992. Understanding hunger and developing indicators to assess it in women and children. Journal of Nutrition Education 24: 36-45.

Shariff, Z.M. \& Khor, G.L. 2008. Household food insecurity and coping strategies in a poor rural community in Malaysia. Nutrition Research and Practice 2(1): 26-34.

Wehler, C.A., Scott, R.I. \& Anderson, J.J. 1994. Development and testing process of the Community Childhood Hunger Identification Project scaled hunger measure and its application for a general population survey. Washington DC: Department of Health and Human Services.

Yamane, T. 1967. Statistics: An introductory analysis. Edition 2. New York: Harper and Row.

Zalilah MS 1998. Growth status determinants of school age children from primarily lowincome households in the urban area of Kuala Lumpur, Malaysia: A focus on intrahousehold factors. PH.D Dissertation, Michigan State University of USA .

Zalilah, M.S. \& Ang, M. 2001. Assessment of food insecurity among low income households in Kuala Lumpur using the Radimer/ Cornell food insecurity instrument - A validation study. Malaysian Journal of Nutrition 7: 15-32. 